\title{
MTHFR C677T, Prothrombin G20210A, and Factor V Leiden (G1691A) Polymorphism and Beta- Thalassemia Risk: A Meta-Analysis
}

\author{
Nitu Nigam ${ }^{1}$, Prithvi K. Singh ${ }^{2}$, Monica Agrawal ${ }^{3}$, Sanjay Nigam ${ }^{4}$, Harish Gupta ${ }^{5}$, Shailendra Saxena 6
}

1. Center for Advance Research (Cytogenetics Lab), King George's Medical University, Lucknow, IND 2. Center for Advance Research (Cytogenetic Lab), King George's Medical University, Lucknow, IND 3. Obstetrics and Gynaecology, King George's Medical University, Lucknow, IND 4. Pathology, Saraswati Medical College, Unnao, IND 5. Medicine, King George's Medical University, Lucknow, IND 6. Center for Advance Research, King George's Medical University, Lucknow, IND

Corresponding author: Nitu Nigam, nigamnitu@gmail.com

\section{Abstract}

\section{Background}

Beta ( $\beta$ )-thalassemia major patients frequently suffer from many vascular problems. Thrombophilia is a blood disorder that comprises imbalances in the blood coagulating factor due to ecological and hereditary components. Previous evidence shows that thrombosis is the commonest risk in beta-thalassemia patients. Several studies have examined that MTHFR C677T, prothrombin G20210A (PT G20210A), and Factor V Leiden G1691A (FVL G1691A) polymorphism play a crucial role in the development of $\beta$-thalassemia major, yet the result was questionable and uncertain. Therefore, in this study, we executed the correlation between these gene polymorphisms with $\beta$-thalassemia major patients.

\section{Methods}

Suitable keywords were used to search related articles in PubMed, Google Scholar, and Web of Science. In this random-effects meta-analysis, we analyzed the odds ratio (OR) for the estimation of risk.

\section{Results}

A total of nine research articles with $645 \beta$-thalassemia major patients and 989 healthy controls were incorporated in this meta-analysis. The pooled OR was assessed in MTHFR C677T, PT G20210A, and FVL G1691A polymorphism. This random-effects meta-analysis demonstrated that MTHFR C677T, PT G20210A, and FVL G1691A gene polymorphism did not significantly associate with $\beta$-thalassemia major. Moreover, the heterogeneity was significantly found in genotype CC vs CT+TT C677T $\left(\mathrm{I}^{2}=61 \%\right)$ and allele $\mathrm{C}$ vs $\mathrm{T}$ ( $\mathrm{I}^{2}=71 \%$ ) of MTHFR and genotype GG vs GA $\left(\mathrm{I}^{2}=95 \%\right), \mathrm{GG}$ vs $\mathrm{GA}+\mathrm{AA}\left(\mathrm{I}^{2}=95 \%\right), \mathrm{GA}$ vs GG+AA $\left(\mathrm{I}^{2}=95 \%\right)$, and allele G vs A ( $\left.\mathrm{I}^{2}=93 \%\right)$ of FVL G1691A.

Received 07/30/2020

Review began 08/02/2020 Review ended 09/12/2020 Published 09/30/2020

๑) Copyright 2020

Nigam et al. This is an open access article distributed under the terms of the Creative Commons Attribution License CC-BY 4.0., which permits unrestricted use, distribution, and reproduction in any medium, provided the original author and source are credited.

\section{Conclusion}

The results of this meta-analysis show that MTHFR C677T, prothrombin G20210A, and Factor V Leiden (G1691A) gene polymorphism are not a risk factor for $\beta$-thalassemia major.

Categories: Genetics, Pediatrics, Public Health

Keywords: gene polymorphism, mthfr, prothrombin, factor v leiden, $\beta$-thalassemia

\section{Introduction}

Beta $(\beta)$-thalassemia major is a single genetic disease affected by mutations in $\beta$-globin genes. These mutation causes a complete deficiency or reduces the formation of $\beta$-globin chains [1]. This disease is an incredible social medical issue in India, where the carrier rate was 5\%-7\%, and globally, it was $4.4 \%$ [2-3]. $\beta$ thalassemia comprises a wide assortment of diseases in three stages, i.e. minor, intermedia, and major, in which major is a severe blood transfusion-dependent disorder [4].

Highly thromboembolic events have been associated with $\beta$-thalassemia, which leads to the thrombosis of arterial or venous blood [5-6]. Various multicenter studies demonstrated the incidence of thromboembolic events, ranging from $1.1 \%$ to $5.3 \%$, which were observed in $\beta$-thalassemia [7-9]. Till now, the process of hypercoagulability is not clear. Previously, various studies reported that the hypercoagulability in $\beta$ thalassemia patients is associated with learned risk factors, including iron overload, hypothyroidism, splenectomy, abnormal liver function, platelet abnormalities, cardiopulmonary abnormalities, and reduced levels of natural anticoagulants [10-12]. Moreover, a study reported that methylenetetrahydrofolate reductase (MTHFR), prothrombin (PT), and Factor V Leiden (FVL) gene polymorphism were predisposing 
MTHFR C667T gene polymorphism altered the function of enzymes and increased the risk of thrombosis [13]. A previous study reported that inherited thrombophilic mutations, such as MTHFR C677T, were significantly associated with hyperhomocysteinemia [13-14]. FVL G1691A polymorphism opposes stimulated protein $\mathrm{C}$ and increases the incidence of thrombosis. The most predominant acquired FVL gene affects thrombosis with the segregation of autosomal dominant genes. The heterozygous mutation of FVL G1691A gene polymorphism increases the incidence of thromboembolic events from $3 \%$ to $5 \%$, whereas homozygous mutation is significantly higher disposed to thrombosis (50\%-100\%) [15-18]. The 3'UTR of PT G20210A (PT G20210A) polymorphism was significantly correlated with a high risk of thrombosis [15-20].

Various epidemiological studies have explored the associations of the MTHFR C677T, PT G20210A, and FVL G1691A gene polymorphism with $\beta$-thalassemia. Still, the outcomes of the studies were conflicting and indecisive. In light of the above evidence, we executed this meta-analysis of accessible articles connecting MTHFR C677T, PT G20210A, and FVL G1691A gene polymorphism to the risk of $\beta$ - thalassemia.

\section{Materials And Methods \\ Setting and study design}

This meta-analysis study was done in the Center for Advance Research (CFAR), Cytogenetics Lab, King George's Medical University, Lucknow.

\section{Identification and methods: search and selection of studies}

$\beta$-thalassemia related articles were independently recognized by investigators from PubMed, Google, and Web of Science. The search terms were as follows: (MTHFR C677T OR Methylenetetrahydrofolate Reductase C677T OR Prothrombin G20210A OR PT G20210A OR PRTG20210A OR Factor V Leiden G1691A OR FVL G1691A AND (polymorphism OR Single nucleotide gene polymorphism OR SNP OR allele OR genotype) AND (thalassemia OR beta-thalassemia OR $\beta$ - thalassemia OR beta-thalassemia major OR $\beta$ - thalassemia major OR $\beta$ - TM). Moreover, the references of all articles and reviews were manually searched for extra appropriate studies.

Results were restricted to MTHFR C677T, PT G20210A, and FVL G1691A gene polymorphism and $\beta$ thalassemia major in humans. A total of 780 articles were identified in PubMed, Google, and Web of Science. Inclusion criteria for the selection and inclusion of studies were: i) Case-control study of $\beta$-thalassemia patients and controls (healthy); (2) MTHFR C677T, PT G20210A, and FVL G1691A gene polymorphism; (3) Published articles; (4) Full article in English; (5) Studies with the expression of MTHFR C677T, PT G20210A, and FVL G1691A gene, and studies on animals or in the lab were excluded. The association of MTHFR (C677T), PT (G20210A), and FVL (G1691A) gene with $\beta$-thalassemia and control was the main concern for the selection of studies.

\section{Data collection}

Data were extracted by authors individually from articles text, figures, or tables in each published article. The above-mentioned details were collected from individual studies, i.e., types of SNP, the technique for polymorphism, and the number of patients and controls (Table 1). 


\section{Cureus}

\begin{tabular}{|c|c|c|c|c|c|}
\hline Study/Year & Types of SNP & Country & $\begin{array}{l}\text { Cases }(\beta- \\
\text { thalassemia) }\end{array}$ & Controls & Methods \\
\hline $\begin{array}{l}\text { Al-Sweedan et al., } \\
2009\end{array}$ & $\begin{array}{l}\text { MTHFR C677T, Prothrombin G20210A, Factor V } \\
\text { Leiden G1691A }\end{array}$ & Jordan & 100 & 100 & $\begin{array}{l}\text { PCR- } \\
\text { RFLP }\end{array}$ \\
\hline Mustafa et al., 2009 & MTHFR C677T & Kuwait & 50 & 50 & $\begin{array}{l}\text { PCR- } \\
\text { RFLP }\end{array}$ \\
\hline Rania et al., 2016 & MTHFR C677T & $\begin{array}{l}\text { Eastern } \\
\text { Algeria }\end{array}$ & 8 & 10 & $\begin{array}{l}\text { PCR- } \\
\text { RFLP }\end{array}$ \\
\hline $\begin{array}{l}\text { Abd-Elmawla et al., } \\
2016\end{array}$ & MTHFR C677T & Egypt & 66 & 66 & $\begin{array}{l}\text { PCR- } \\
\text { RFLP }\end{array}$ \\
\hline Rahimi et al., 2008 & $\begin{array}{l}\text { MTHFR C677T, Prothrombin G20210A, Factor V } \\
\text { Leiden G1691A }\end{array}$ & Iran & 151 & 180 & $\begin{array}{l}\text { PCR- } \\
\text { RFLP }\end{array}$ \\
\hline Bagher et al., 2017 & $\begin{array}{l}\text { MTHFR C677T, Prothrombin G20210A, Factor V } \\
\text { Leiden G1691A }\end{array}$ & Iran & 158 & 104 & $\begin{array}{l}\text { PCR- } \\
\text { RFLP }\end{array}$ \\
\hline Pandey et al., 2012 & $\begin{array}{l}\text { MTHFR C677T, Prothrombin G20210A, Factor V } \\
\text { Leiden G1691A }\end{array}$ & India & 75 & 297 & $\begin{array}{l}\text { PCR- } \\
\text { RFLP }\end{array}$ \\
\hline Nefissi et al., 2018 & MTHFR C677T, Prothrombin G20210A & Tunisia & 4 & 64 & $\begin{array}{l}\text { PCR- } \\
\text { RFLP }\end{array}$ \\
\hline $\begin{array}{l}\text { Samarah et al., } \\
2018\end{array}$ & Prothrombin G20210A & Palestine & 33 & 118 & $\begin{array}{l}\text { PCR- } \\
\text { RFLP }\end{array}$ \\
\hline
\end{tabular}

TABLE 1: Characteristics/details of included studies for meta-analysis

\section{Data synthesis}

The data were obtained from every study: title of the article, name of the principal author's, journal name, date of publication, name of nation, and strategy utilized for genotyping.

\section{Statistical analysis}

RevMan 5.3 (Review Manager version 5.3) of the Cochrane Collaboration, London, United Kingdom, was used for statistical interpretation. The odds ratio (OR) was used for risk assessment. In addition, the heterogeneity among studies was estimated by the $\mathrm{Q}$ test with $\mathrm{p}$-values $<0.05$ and $>50 \% \mathrm{I} 2$ was considered significant. Initially, the associations-based studies were analyzed; after that, the subgroup examinations by SNP type were accomplished to find the SNP type-specific impacts.

\section{Results}

\section{Search results}

The search outcomes of published articles have been shown in Figure 1. Initially, 780 pieces of literature were searched and saved. After screening the title and abstracts of the articles, of a total of 765 pieces of literature records were excluded from this meta-analysis due to the non-relevance with the theme, duplicated works, and review articles. Furthermore, six published articles were also left out after the screening of record abstracts. After scanning of abstracts and titles, 15 articles were identified for full-text scrutiny. Numerous studies were excluded due to the unavailability of necessary data and controls. Hence, a total of nine studies encompassing $645 \beta$-thalassemia major patients and 989 healthy controls were included in the meta-analysis. Finally, nine articles [14,21-28], eight studies focusing on polymophism of MTHFR C677T, six studies on prothrombin G20210A, and four studies on Factor V Leiden G1691A were considered for meta-analysis (Figure 1). 


\section{Cureus}

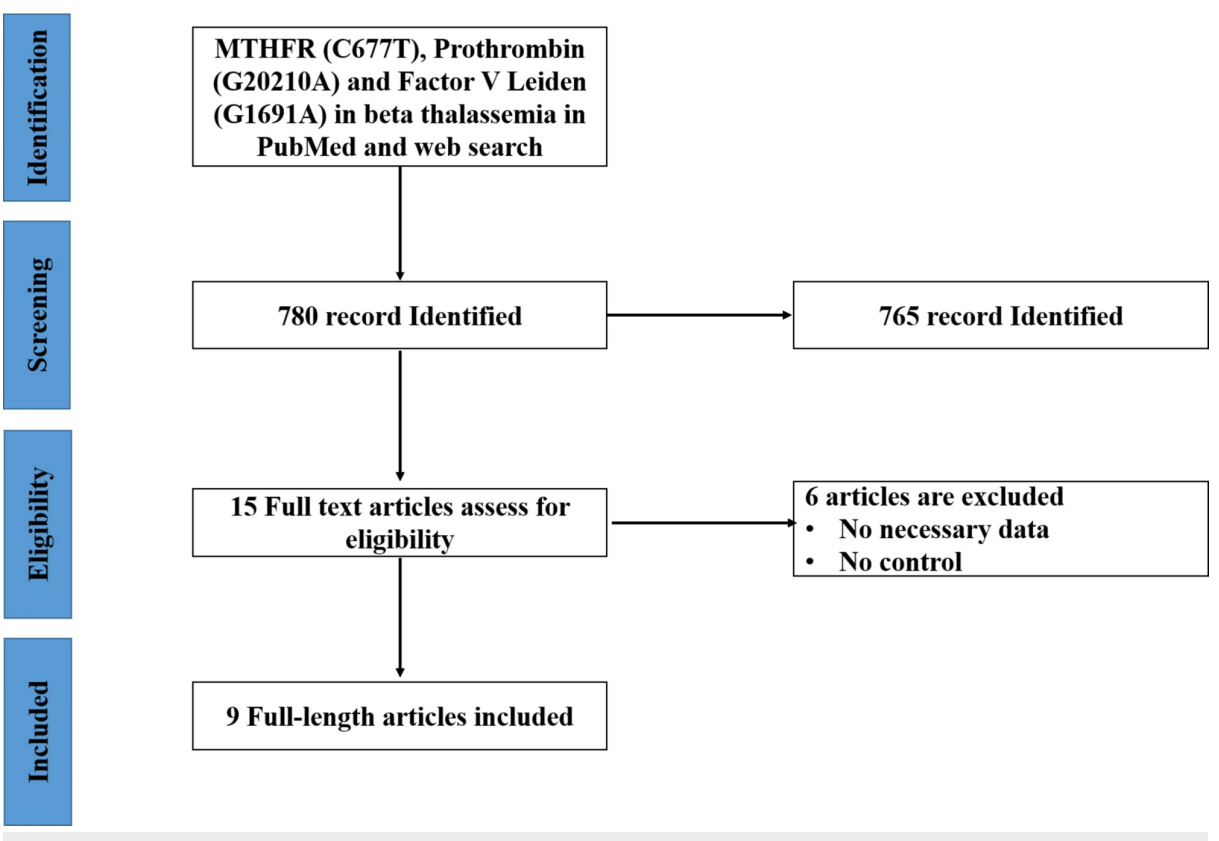

FIGURE 1: Flow diagram of article searching, screening, eligibility, and included or selection process

\section{MTHFR C677T gene polymorphism and the risk of $\beta$-thalassemia}

For MTHFR C677T polymorphism, a total of eight studies, including $612 \beta$-thalassemia patients and 871 healthy controls were examined (Table 1). Deviations from Hardy-Weinberg Equilibrium (HWE) were observed in only one study [28] while the other eight studies were in agreement with HWE (Table 2). Random effects meta-analysis demonstrated that MTHFR C677T gene polymorphism did not found significantly associated with $\beta$-thalassemia risk [CC vs CT: OR 0.92 , CI $(0.63-1.34), \mathrm{p}=0.68$; CT vs TT: OR 0.83 , $\mathrm{CI}(0.49-1.42), \mathrm{p}=0.50$; TT vs CC: OR1.45 CI(0.70-2.98), $\mathrm{p}=0.31$; CC vs CT+TT: OR 0.87, CI(0.57-1.33), 0.52; CT vs TT+CC: OR 1.08, CI(0.76-1.54), $\mathrm{p}=0.67$; TT vs CC+CT: OR $1.46, \mathrm{CI}(0.73-2.89), \mathrm{p}=0.28$ and $\mathrm{C}$ vs T: OR 0.86 , $\mathrm{CI}(0.58-1.28)]$, as shown in Table 3 and Figure 2 . Moreover, the heterogeneity was significantly found in genotype CC vs CT+TT (I2=61\%) and allele C vs T (I2=71\%) analyzed in this meta-analysis (Table 3). 


\section{Cureus}

\begin{tabular}{|c|c|c|c|c|c|c|c|c|c|c|}
\hline \multirow{2}{*}{ Study } & \multicolumn{5}{|c|}{ Cases } & \multicolumn{5}{|c|}{ Controls } \\
\hline & \multicolumn{3}{|c|}{ Genotype } & \multicolumn{2}{|l|}{ Allele } & \multicolumn{3}{|c|}{ Genotype } & \multicolumn{2}{|c|}{ Allele } \\
\hline & $\mathrm{CC}$ & CT & $\mathrm{TT}$ & C & $\mathrm{T}$ & $\mathrm{CC}$ & CT & TT & C & $\mathrm{T}$ \\
\hline Al-Sweedan et al., 2009 & 62 & 33 & 5 & 157 & 43 & 63 & 32 & 5 & 158 & 42 \\
\hline Mustafa et al., 2009 & 32 & 16 & 2 & 80 & 20 & 24 & 21 & 5 & 69 & 31 \\
\hline Rania et al., 2016 & 5 & 3 & 0 & 13 & 3 & 6 & 2 & 2 & 14 & 6 \\
\hline Abd-Elmawla et al., 2016 & 48 & 10 & 8 & 106 & 26 & 60 & 4 & 2 & 124 & 8 \\
\hline Rahimi et al., 2008 & 75 & 66 & 10 & 216 & 86 & 93 & 74 & 13 & 260 & 100 \\
\hline Bagher et al., 2017 & 100 & 49 & 9 & 249 & 67 & 57 & 44 & 3 & 158 & 50 \\
\hline Pandey et al., 2012 & 55 & 16 & 4 & 126 & 24 & 257 & 37 & 3 & 551 & 43 \\
\hline Nefissi et al., 2018 & 1 & 3 & 0 & 5 & 3 & 15 & 48 & 1 & 78 & 50 \\
\hline \multicolumn{11}{|l|}{ Prothrombin G20210A } \\
\hline & $\mathrm{GG}$ & GA & AA & $\mathrm{G}$ & A & GG & GA & AA & G & A \\
\hline Rahimi et al., 2008 & 149 & 2 & 0 & 300 & 2 & 174 & 6 & 0 & 354 & 6 \\
\hline Al-Sweedan et al., 2009 & 94 & 6 & 0 & 198 & 6 & 95 & 5 & 0 & 195 & 5 \\
\hline Nefissi et al., 2018 & 16 & 0 & 0 & 32 & 0 & 57 & 7 & 0 & 121 & 7 \\
\hline Bagher et al., 2017 & 158 & 0 & 0 & 316 & 0 & 103 & 1 & 0 & 207 & 1 \\
\hline Samarah et al., 2018 & 29 & 4 & 0 & 62 & 4 & 112 & 6 & 0 & 230 & 6 \\
\hline Pandey et al., 2012 & 75 & 0 & 0 & 150 & 0 & 297 & 0 & 0 & 594 & 0 \\
\hline \multicolumn{11}{|l|}{ Factor V Leiden G1691A } \\
\hline & GG & GA & AA & G & A & GG & GA & AA & G & A \\
\hline Rahimi et al., 2008 & 143 & 7 & 1 & 293 & 9 & 175 & 5 & 0 & 355 & 5 \\
\hline Al-Sweedan et al., 2009 & 78 & 21 & 1 & 177 & 23 & 19 & 80 & 1 & 118 & 82 \\
\hline Bagher et al., 2017 & 151 & 7 & 0 & 309 & 7 & 98 & 3 & 2 & 199 & 7 \\
\hline Pandey et al., 2012 & 66 & 8 & 1 & 140 & 10 & 289 & 8 & 0 & 586 & 8 \\
\hline
\end{tabular}

TABLE 2: Distributions of genotypes and allele frequencies of MTHFR (C677T), prothrombin (G20210A), and Factor V Leiden (G1691A) in $\beta$-thalassemia cases and controls 


\section{Cureus}

\begin{tabular}{|c|c|c|c|c|c|c|c|}
\hline \multirow{2}{*}{ Variable } & \multicolumn{3}{|l|}{ Main effects } & \multicolumn{4}{|c|}{ Heterogeneity } \\
\hline & OR $(95 \% \mathrm{Cl})$ & z Score & P-value & $\mathrm{Tau}^{2}$ & $\mathrm{Chi}^{2}$ & P-value & $I^{2}$ statistic \\
\hline CC vs CT & $0.92(0.63-1.34)$ & 0.44 & 0.68 & 0.12 & 12.82 & 0.08 & $45 \%$ \\
\hline CT vs TT & $0.83(0.49-1.42)$ & 0.68 & 0.50 & 0.0 & 6.31 & 0.50 & $0 \%$ \\
\hline TT vs CC & $1.45(0.70-2.98)$ & 1.00 & 0.31 & 0.40 & 11.65 & 0.11 & $40 \%$ \\
\hline $\mathrm{CC}$ vs $\mathrm{CT}+\mathrm{TT}$ & $0.87(0.57-1.33)$ & 0.64 & 0.52 & 0.20 & 18.14 & $0.01^{*}$ & $61 \%$ \\
\hline CT vs $\mathrm{TT}+\mathrm{CC}$ & $1.08(0.76-1.54)$ & 0.43 & 0.67 & 0.09 & 11.84 & 0.11 & $41 \%$ \\
\hline TT vs $\mathrm{CC}+\mathrm{CT}$ & $1.46(0.73-2.89)$ & 1.08 & 0.28 & 0.33 & 10.96 & 0.14 & $36 \%$ \\
\hline C vs T & $0.86(0.58-1.28)$ & 0.74 & 0.46 & 0.20 & 23.74 & $0.001^{*}$ & $71 \%$ \\
\hline
\end{tabular}

TABLE 3: Subgroup analyses for MTHFR C677T polymorphism and $\beta$-thalassemia

*=Significant
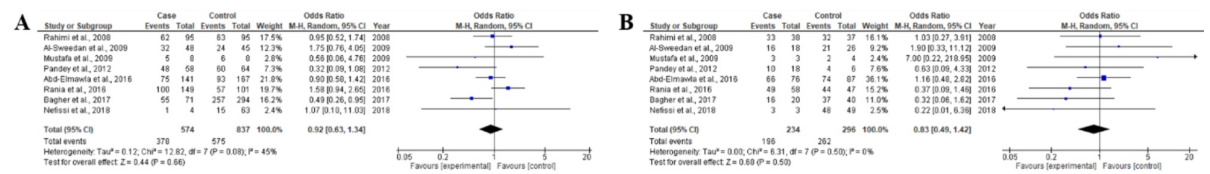

C
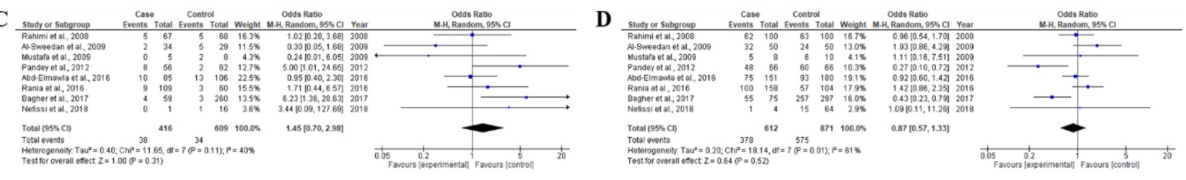

$\mathbf{E}$
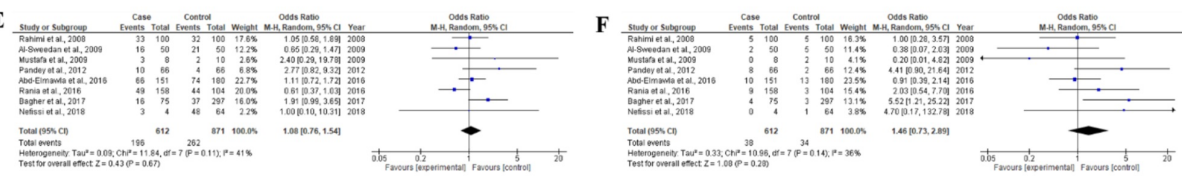

G

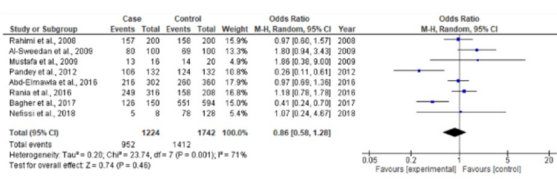

FIGURE 2: Forest plots of association between MTHFR C677T polymorphism and $\beta$-thalassemia for all genotype and allele frequencies

(A) CC vs. CT genotype, (B) CT vs. TT genotype, (C) TT vs. CC genotype, (D) CC vs. CT+TT genotype, (E) CT vs. CC+TT genotype, (F) TT vs. CC+CT genotype, (G) $C$ vs. T allele

The squares and horizontal lines parallel to the OR and $95 \% \mathrm{Cl}$ for study. The squares area shows the weight (inverse of the variance). The diamond area shows the overall OR and $95 \% \mathrm{Cl}$.

MTHFR, methylenetetrahydrofolate reductase; OR, odds ratio; $\mathrm{Cl}$, confidence interval

\section{Prothrombin G20210A gene polymorphism and the risk of $\beta$ - thalassemia}

For prothrombin G20210A polymorphism, a total of six studies, including $521 \beta$-thalassemia patients and 863 healthy controls were examined (Table 1). Deviations from HWE were not observed in any studies, all six studies were in agreement with HWE (Table 2). This random-effects meta-analysis demonstrated that prothrombin G20210A gene polymorphism was not found significantly associated with $\beta$-thalassemia risk [GG vs GA: OR 1.11, CI(0.45-2.73), $\mathrm{p}=0.82$; GG vs GA+AA: OR 1.11, CI(0.45-2.73), $\mathrm{p}=0.82$; GA vs GG+AA: OR $0.90, \mathrm{CI}(0.37-22.21), \mathrm{p}=0.82$; and $\mathrm{G}$ vs A: OR 1.10, $\mathrm{CI}(0.46-2.62), \mathrm{p}=0.83$ ], as shown in Table 4 and Figure 3 . 


\section{Cureus}

Moreover, heterogeneity was also not significantly found in genotype and allele prothrombin G20210A analyzed in this meta-analysis (Table 4).

\begin{tabular}{|c|c|c|c|c|c|c|c|}
\hline \multirow{2}{*}{ Variable } & \multicolumn{3}{|l|}{ Main effects } & \multicolumn{4}{|c|}{ Heterogeneity } \\
\hline & OR (95\% Cl) & z Score & P-value & $\mathrm{Tau}^{2}$ & $\mathrm{Chi}^{2}$ & $\mathrm{P}$-value & $\mathrm{I}^{2}$ statistic \\
\hline GG vs GA & $1.11(0.45-2.73)$ & 0.23 & 0.82 & 0.26 & 5.32 & 0.26 & $25 \%$ \\
\hline GA vs $A A$ & - & - & - & - & - & - & - \\
\hline AA vs GG & - & - & - & - & - & - & - \\
\hline GG vs $G A+A A$ & $1.11(0.45-2.73)$ & 0.23 & 0.82 & 0.26 & 5.32 & 0.26 & $25 \%$ \\
\hline GA vs $G G+A A$ & $0.90(0.37-22.21)$ & 0.23 & 0.82 & 0.26 & 5.32 & 0.26 & $25 \%$ \\
\hline AA vs $G G+G A$ & - & - & - & - & - & - & - \\
\hline G vs $A$ & $1.10(0.46-2.62)$ & 0.22 & 0.83 & 0.22 & 5.14 & 0.27 & $22 \%$ \\
\hline
\end{tabular}

TABLE 4: Subgroup analyses for prothrombin G20210A polymorphism and $\beta$-thalassemia
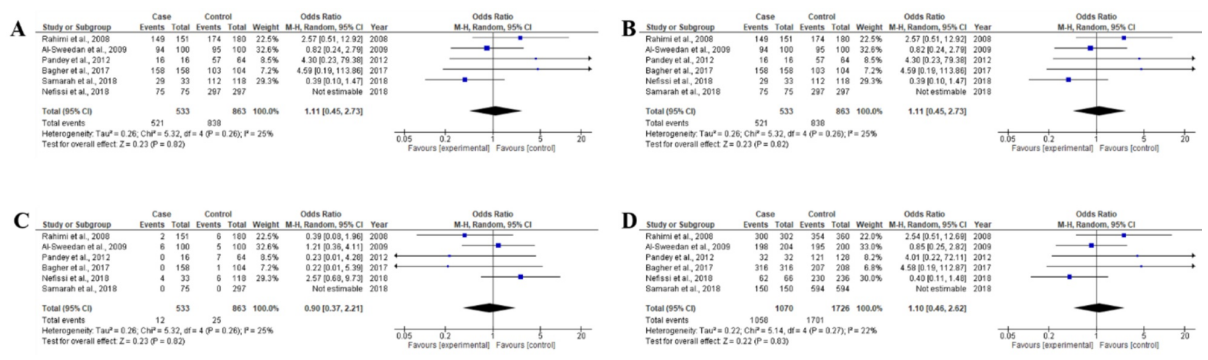

FIGURE 3: Forest plots of association between prothrombin G20210A polymorphism and $\beta$-thalassemia for all genotype and allele frequencies

(A) GG vs. GA genotype, (B) GG vs. GA+AA genotype, (C) GA vs. GG+AA genotype, (D) G vs. A allele

The squares and horizontal lines parallel the $\mathrm{OR}$ and $95 \% \mathrm{Cl}$ for the study. The square areas show the weight (inverse of the variance). The diamond area shows the overall OR and $95 \% \mathrm{CI}$.

OR, odds ratio; $\mathrm{Cl}$, confidence interval

\section{Prothrombin G20210A gene polymorphism and the risk of $\beta$ - thalassemia}

For prothrombin G20210A polymorphism, a total of six studies, including $521 \beta$-thalassemia patients and 863 healthy controls were examined (Table 1). Deviations from HWE were not observed in any studies, all six studies were in agreement with HWE (Table 2). This random-effects meta-analysis demonstrated that prothrombin G20210A gene polymorphism was not found to be significantly associated with $\beta$-thalassemia risk [GG vs GA: OR 1.11, CI(0.45-2.73), $\mathrm{p}=0.82$; GG vs GA+AA: OR 1.11, $\mathrm{CI}(0.45-2.73), \mathrm{p}=0.82$; $\mathrm{GA}$ vs GG+AA: OR 0.90, $\mathrm{CI}(0.37-22.21), \mathrm{p}=0.82$; and $\mathrm{G}$ vs A: OR $1.10, \mathrm{CI}(0.46-2.62), \mathrm{p}=0.83$ ] as shown in Table 4 and Figure 3. Moreover, heterogeneity was also not significantly found in the genotype and allele prothrombin G20210A analyzed in this meta-analysis (Table 4 ).

\section{Factor V Leiden G1691A gene polymorphism and the risk of $\beta$ - thalassemia}

For Factor V Leiden G1691A polymorphism, a total of four studies, including $484 \beta$-thalassemia patients and 681 healthy controls, were examined (Table 1). Deviations from HWE were observed in two studies $[25,27]$ while the other two studies were in agreement with HWE (Table 2). This random-effects metaanalysis demonstrated that prothrombin G20210A gene polymorphism was not found to be significantly associated with $\beta$-thalassemia risk [GG vs GA: OR 1.11, CI(0.12-10.44), $\mathrm{p}=0.93$; GA vs AA: OR 0.75, CI(0.144.15), $\mathrm{p}=0.74$; AA vs GG: OR 1.02, CI (0.2-8.58) p=0.98; GG vs GA+AA: OR 1.17, CI (0.13-10.30), p=0.89; GA vs 


\section{Cureus}

GG+AA: OR 0.91, CI (0.10-8.33), p=0.93; AA vs GG+GA: OR 1.44, CI (0.22-9.41), 0.70 and G vs A: OR 0.95, CI $(0.18-5.06), \mathrm{p}=0.95]$ as shown in Table 5 and Figure 4 . Moreover, heterogeneity was significantly found in genotype GG vs GA (I2=95\%), GG vs GA+AA (I2=95\%), GA vs GG+AA (I2=95\%), and allele G vs A (I2=93\%) analyzed in this meta-analysis (Table 5).

\begin{tabular}{|c|c|c|c|c|c|c|c|}
\hline \multirow{2}{*}{ Variable } & \multicolumn{3}{|l|}{ Main effects } & \multicolumn{4}{|c|}{ Heterogeneity } \\
\hline & OR (95\% Cl) & z Score & P-value & $\mathrm{Tau}^{2}$ & $\mathrm{Chi}^{2}$ & $P$-value & I $^{2}$ statistic \\
\hline GG vs $G A$ & $1.11(0.12-10.44)$ & 0.009 & 0.93 & 4.91 & 57.66 & $<0.00^{*}$ & $95 \%$ \\
\hline GA vs $A A$ & $0.75(0.14-4.15)$ & 0.33 & 0.74 & 0.39 & 3.45 & 0.33 & $13 \%$ \\
\hline AA vs $G G$ & $1.02(0.2-8.58)$ & 0.02 & 0.98 & 2.26 & 5.77 & 0.12 & $48 \%$ \\
\hline GG vs $G A+A A$ & $1.17(0.13-10.30)$ & 0.14 & 0.89 & 4.66 & 60.9 & $<0.00^{*}$ & $95 \%$ \\
\hline GA vs $G G+A A$ & $0.91(0.10-8.33)$ & 0.09 & 0.93 & 4.82 & 56.93 & $<0.001^{*}$ & $95 \%$ \\
\hline$A A$ vs $G G+G A$ & $1.44(0.22-9.41)$ & 0.38 & 0.70 & 1.24 & 4.53 & 0.21 & $34 \%$ \\
\hline G vs $A$ & $0.95(0.18-5.06)$ & 0.06 & 0.95 & 2.69 & 44.48 & $<0.001^{*}$ & $93 \%$ \\
\hline
\end{tabular}

TABLE 5: Subgroup analyses for Factor V Leiden G1691A polymorphism and $\beta$-thalassemia
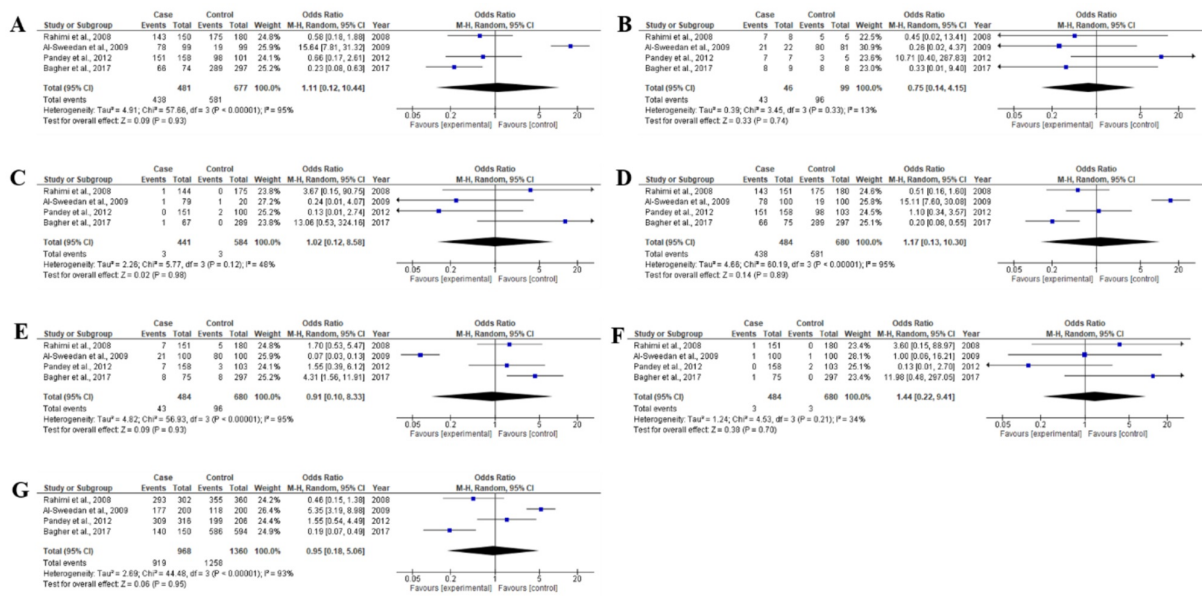

FIGURE 4: Forest plots of association between Factor V Leiden G1691A polymorphism and $\beta$-thalassemia for all genotype and allele frequencies

(A) GG vs. GA genotype, (B) GA vs. AA genotype, (C) AA vs. GG genotype, (D) GG vs. GA+AA genotype, (E) $G A$ vs. $G G+A A$ genotype, (F) AA vs. $G G+G A$ genotype, (G) $G$ vs. A allele

The squares and horizontal lines are parallel to the OR and $95 \% \mathrm{Cl}$ for the study. The squares area shows the weight (inverse of the variance). The diamond area shows the overall OR and $95 \% \mathrm{Cl}$.

OR, odds ratio; $\mathrm{Cl}$, confidence interval

\section{Discussion}

Meta-analysis is a potent analyzing tool for accumulative data with low and small power studies. In this study, we explore the correlation of MTHFR C677T, PT G20210A, and FVL G1691A gene polymorphism with $\beta$-thalassemia major patients. Here, we meta-analyzed the published information about the polymorphism of MTHFR C677T of $612 \beta$-Thalassemia major patients from eight published studies and, particularly, the changes in allele and genotype occurrences of MTHFR C677T gene polymorphism in patients as compared with controls. We also meta-analyzed the published data about the polymorphism of PT G20210A and FVL G1691A of 521 and $484 \beta$-thalassemia major patients from six and four studies, respectively, and compared 
the genotype and allele frequencies of PT G20210A and FVL G1691A polymorphism in patients as compared with controls.

In this random-effects meta-analysis, we did not find an association between MTHFR C677T, PT G20210A, and FVL G1691A gene polymorphism with $\beta$-Thalassemia major patients as compared to controls. Overall, it can be concluded from general and subgroup analyses that the MTHFR C677T, PT G20210A, and FVL G1691A gene polymorphisms may not play an important role in the pathogenesis of a thromboembolic event. Still, there is not a sufficient amount of relevant studies to give a safe and good assumption. In the future, however, more well-designed studies with a bigger sample size and metacentric studies will be necessary to validate the current outcomes.

In meta-analyses, heterogeneity is one of the significant factors. In this study, heterogeneity was significantly observed in genotype CC vs CT+TT (I2=61\%) and allele C vs T (I2=71\%) of MTHFR C677T polymorphism and genotype GG vs GA (I2=95\%), GG vs GA+AA (I2=95\%), GA vs GG+AA (I2=95\%), and allele G vs A (I2=93\%) FVL G1691A gene polymorphism. However, heterogeneity was not significantly found in other genotypes of MTHFR C677T and FVL G1691A and the genotype and alleles of PT G20210A gene polymorphism.

A previous study reported that the T allele (mutant allele) frequencies of MTHFR C677T polymorphism were $21.5 \%$ and $21 \%$ in $\beta$-Thalassemia major and healthy controls, respectively. The frequency of MTHFR C677T mutations was marginally greater but not significantly different between $\beta$-thalassemia major patients and controls $[25,27]$. The frequencies of the allele and genotype of MTHFR C677T gene polymorphism were not significantly associated with $\beta$-thalassemia $[23,25-26]$.

The mutation of the MTHFR C677T gene was not statistically correlated with an increased risk of thrombophilia in patients with $\beta$-thalassemia major [14,22]. Contrarily, Elmawla et al. (2016) reported that the polymorphism of the MTHFR C677T gene was statistically significantly correlated with $\beta$-thalassemia [21]. The frequencies of the mutant A allele of FVL G1691A gene polymorphism was $11.5 \%$ in $\beta$-thalassemia major and $10.5 \%$ in controls. The frequencies of $\mathrm{G}$ and $\mathrm{A}$ alleles were not significantly different between groups [25]. The incidence of the FVL G1691A gene polymorphism was found more in $\beta$-thalassemia patients but not significantly different from healthy controls. The A allele (mutant allele) frequencies of the PT G20210A mutation was 3\% and 2.5\% in $\beta$-thalassemia major and healthy controls, respectively; differences in between were not statistically significant [25]. Pandey et al. (2012) show that the occurrence of heterozygous PT G20210A polymorphism was not associated in patients in the $\beta$-thalassemia major and controls groups [27]. Limited studies demonstrated that the increased frequency of thrombophilic mutation has not been associated with thalassemia patients [12,29]. However, the heterozygote genotype of FVL G1691A and PT G20210A and the frequencies of recurrent thromboembolism was double in $\beta$-thalassemia patients [30]. The heterozygous and homozygous genotypes of FVL was statistically significantly correlated with the high risk of thrombosis [17].

When interpreting the meta-analysis outcomes, various limitations should be considered. First of all, the appropriate studies were limited in number. To limit the conceivable outcomes of distribution bias, published articles were incorporated. Thereafter, the present results were based on unadjusted appraisals. Finally, our analyses did not reflect the possibility of linkage disequilibrium and interaction between genegene or SNP-SNP.

\section{Conclusions}

The results of the present meta-analysis suggest that the genotype and allele frequencies of MTHFR C677T, prothrombin G20210A (PT G20210A), and Factor V Leiden G1691A (FVL G1691A) gene polymorphism were not significantly correlated with the risk for the development of $\beta$-thalassemia major. However, the outcomes of this meta-analysis were based on mutation (single gene polymorphism), and significant heterogeneity was likewise identified. Therefore, the outcomes of the current study should be interpreted and need further well-designed studies.

\section{Additional Information \\ Disclosures}

Human subjects: All authors have confirmed that this study did not involve human participants or tissue. Animal subjects: All authors have confirmed that this study did not involve animal subjects or tissue. Conflicts of interest: In compliance with the ICMJE uniform disclosure form, all authors declare the following: Payment/services info: All authors have declared that no financial support was received from any organization for the submitted work. Financial relationships: All authors have declared that they have no financial relationships at present or within the previous three years with any organizations that might have an interest in the submitted work. Other relationships: All authors have declared that there are no other relationships or activities that could appear to have influenced the submitted work.

\section{References}


1. Olivieri NF: The $\beta$-thalassemias. N Engl J Med. 1999, 341:99-109. 10.1056/NEJM199907083410207

2. Thiyagarajan A, Bhattacharya S, Sharma N, Srivastava A, Dhar DK: Need for a universal thalassemia screening programme in India? A public health perspective. J Family Med Prim Care. 2019, 8:1528-1532. 10.4103/jfmpc.jfmpc_90_19

3. Aljeesh YI: Quality of life among thalassemia children patients in the Gaza strip . Am J Nurs Sci. 2016, 5:106113. 10.11648/j.ajns.20160503.15

4. Shams S, Ashtiani MT, Monajemzadeh M, Koochakzadeh L, Irani H, Jafari F, Mohseni A: Evaluation of serum insulin, glucose, lipid profile, and liver function in $\beta$-thalassemia major patients and their correlation with iron overload. Lab Med. 2010, 41:486-489. 10.1309/LMSOEOOUZSII2BNE

5. Cohen AR, Galanello R, Pennell DJ, Cunningham MJ, Vichinsky E: Thalassemia hematology. Am Soc Hematol Educ Program. 2004, 1:14-34. 10.1182/asheducation-2004.1.14

6. Cappellini MD, Robbiolo L, Bottasso BM, Coppola R, Fiorelli AP, Mannucci AP: Venous thromboembolism and hypercoagulability in splenectomized patients with thalassaemia intermedia. Br J Haematol. 2000, 111:467-473.

7. Borgna Pignatti C, Carnelli V, Caruso V, et al.: Thromboembolic events in beta thalassemia major: an Italian multicenter study. Acta Haematol. 1998, 99:76-79. 10.1159/000040814

8. Borgna-Pignatti C, Cappellini MD, De Stefano P, et al.: Survival and complications in thalassemia. Ann N Y Acad Sci. 2005, 1054:40-47. 10.1196/annals.1345.006

9. Moratelli S, De Sanctis V, Gemmati D, Serino ML, Mari R, Gamberini MR, Scapoli GL: Thrombotic risk in thalassemic patients. J Pediatr Endocrinol Metab. 1998, 11:915-921.

10. Panigrahi I, Agarwal S: Thromboembolic complications in beta-thalassemia: beyond the horizon . Thromb Res. 2007, 120:783-789. 10.1016/j.thromres.2007.01.015

11. Barrano B, Bertrand G, Isaja T, Curreri R, Musumeci S: Plasma homocysteine is not involved in the thrombotic risk of beta-thalassemia major patients. Acta Haematol. 2000, 104:148-150. 10.1159/000039752

12. Eldor A, Rachmilewitz EA: The hypercoagulable state in thalassemia. Blood. 2002, 99:36-43. 10.1182/blood.V99.1.36

13. Frosst $\mathrm{P}$, Blom HJ, Milos R, et al.: A candidate genetic risk factor for vascular disease: a common mutation in methylenetetrahydrofolate reductase. Nat Genet. 1995, 10:111-113. 10.1038/ng0595-111

14. Mustafa NY, Marouf R, Al-Humood S, Al-Fadhli SM, Mojiminiyi O: Hypercoagulable state and methylenetetrahydrofolate reductase (MTHFR) C677T mutation in patients with beta-thalassemia major in Kuwait. Acta Haematol. 2010, 123:37-42. 10.1159/000260069

15. Sueta D, Ito M, Uchiba M, et al.: A case of pulmonary thromboembolism due to coagulation factor V Leiden in Japan usefulness of next generation sequencing . Thromb J. 2017, 15:8. 10.1186/s12959-017-0132-6

16. Juul K, Tybjaerg-Hansen A, Schnohr P, Nordestgaard BG: Factor V Leiden and the risk for venous thromboembolism in the adult Danish population. Ann Intern Med. 2004, 140:330-337. 10.7326/0003-4819140-5-200403020-00008

17. Rosendaal FR, Koster T, Vandenbroucke JP, Reitsma PH: High risk of thrombosis in patients homozygous for factor V Leiden (activated protein C resistance). Blood. 1995, 85:1504-1508.

18. Bertina RM, Koeleman BP, Koster T, et al.: Mutation in blood coagulation factor V associated with resistance to activated protein C. Nature. 1994, 369:64-67. 10.1038/369064a0

19. Poort SR, Rosendaal FR, Reitsma PH, Bertina RM: A common genetic variation in the 3 '-untranslated region of the prothrombin gene is associated with elevated plasma prothrombin levels and an increase in venous thrombosis. Blood. 1996, 88:3698-3703.

20. Yoon U, Kwok L, Flessenkaemper I: Bilateral superficial femoral artery thrombosis in a 15-year-old Caucasian male with homozygous prothrombin G20210A genotype and associated antiphospholipid syndrome. Int J Angiol. 2016, 25:100-105. 10.1055/s-0035-1548557

21. Abd-Elmawla MA, Rizk SM, Youssry I, Shaheen AA: Impact of genetic polymorphism of methylenetetrahydrofolate reductase C677T on development of hyperhomocysteinemia and related oxidative changes in Egyptian $\beta$-thalassemia major patients. PLoS One. 2016, 11:0155070. 10.1371/journal.pone.0155070

22. Rahimi Z, Ghaderi M, Nagel RL, Muniz A: Prevalence of thrombotic risk factors among beta-thalassemia patients from Western Iran. J Thromb Thrombolysis. 2008, 26:229-233. 10.1007/s11239-007-0163-0

23. Bagher SM, Hashemi-Soteh, Aliasgharian A, Tafazoli A, Karami H, Kowsaryan M: Frequency of Factor V Leiden, prothrombin G20210A and MTHFR C667T mutations in beta-thalassemia patients compare with normal individuals from north of Iran. J Genom Gene Study. 2018, 1:1-5.

24. Belhaj Nefissi R, Doggui R, Ouali F, Messaoud T, Gritli N: Factor V Leiden G1691A, prothrombin G20210A, and MTHFR C677T and A1298C mutations in patients with sickle cell disease in Tunisia. Hemoglobin. 2018, 42:96-102. 10.1080/03630269.2018.1451340

25. Al-Sweedan SA, Jaradat S, Iraqi M, Beshtawi M: The prevalence of factor V Leiden (G1691A), prothrombin G20210A and methylenetetrahydrofolate reductase C677T mutations in Jordanian patients with betathalassemia major. Blood Coagul Fibrinolysis. 2009, 20:675-678. 10.1097/MBC.0b013e3283315b4f

26. Rania L, Maroua S, Sakina B, Djalila RC, Noureddine A, Dalila S: Genetic and hematological profiles of $\beta$ thalassemias in Eastern Algeria. Sciences \& Technologie C., Biotechnologies. 2016, 44:37-46.

27. Pandey SK, Meena A, Kishor K, Mishra RM, Pandey S, Saxena R: Prevalence of factor V Leiden G1691A, MTHFR C677T, and prothrombin G20210A among Asian Indian sickle cell patients. Clin Appl Thromb Hemost. 2012, 18:320-323. 10.1177/1076029611425830

28. Samarah F, Srour MA: Factor V Leiden G1691A and prothrombin G20210A mutations among Palestinian patients with sickle cell disease. BMC Hematol. 2018, 18:1. 10.1186/s12878-018-0097-0

29. Zalloua PA, Shbaklo H, Mourad YA, Koussa S, Taher A: Incidence of thromboembolic events in Lebanese thalassemia intermedia patients. Thromb Haemost. 2003, 89:767-768.

30. Kahn JE, Veyssier-Belot C, Renier JL, de Mazancourt P, Peltier JY, de Raucourt E: Recurrent thromboembolism in a patient with beta-thalassemia major associated with double heterozygosity for factor V R506Q and prothrombin G20210A mutations. Blood Coagul Fibrinolysis. 2002, 13:461-463. 10.1097/00001721-200207000-00012 